\title{
Online Discussion: Self-repair Enhancement of EFL Learners
}

\author{
Omid Tabatabaei \\ English Department, Najafabad Branch, Islamic Azad University, Najafabad, Iran \\ Email: tabatabaeiomid@yahoo.com \\ Razieh Sharifi \\ English Department, Shahreza Branch, Islamic Azad University, Shahreza, Iran
}

\begin{abstract}
With the rapid development of technologies, on-line learning has gained an increasingly important role in foreign language learning and teaching in recent years. While many studies (e.g., Herring, 1999; Greenfield, 1984) have examined the effects of on-line chatting on students' learning, few have looked into selfrepair of the produced utterances by students in on-line chatting. This study investigated the difference between the interactions in on-line chat rooms and regular classroom discussions, with regard to self-repair, to figure out chatting potentials in enhancing foreign language development. Forty intermediate female students with the age range of 14-18 participated in this study. They were randomly divided into two groups of on-line chatting treatment and face-to-face class treatment, 20 each. The instruments included in this study were a pre-research questionnaire, the Oxford Placement Test (OPT), a pretest and a posttest, Yahoo Messenger Software, and a voice recorder. The data were collected through a pretest-posttest design, transcription of students' discussions, and printouts of the chat sessions. The comparison of on-line chatting and traditional face-to-face class discussions suggested that using on-line chatting could result in progress of learning a foreign language (i.e., accuracy of their speech) through self-repair. Furthermore, according to the findings of this study, on-line chatting provided the participants with a unique opportunity to put their grammatical knowledge into practice through meaningful communication. Moreover, most of the errors the learners repaired belonged to the category of subject-verb agreement, presumably because such errors might jeopardize the accurate speaking. The results of the study may have significant implications for teaching, testing and materials development.
\end{abstract}

Index Terms - on-line discussion, error correction, on-line learning, self-repair, synchronous computermediated communication

\section{INTRODUCTION}

Speaking in a foreign language is very difficult and competence in speaking takes a long time to develop. In order to be able to speak a foreign language learners must master the sound system of the language, have a great knowledge of vocabulary, and put words in correct strings. With increasing globalization among people from different countries, one can see that in order to communicate with one another from different countries around the world, accurate speaking is highly important. Due to the enhanced speed of on-line communication, one can improve speaking skills through World Wide Web's facilities such as on-line learning.

In the past several years, online learning systems have been taking an important part in higher educational systems (Geri \& Gefen, 2007). According to Hiltz and Turoff (2005), online learning is a new social process that is beginning to act as a complete substitute for both distance learning and the traditional face-to-face class. In the last decade, we have been witnessing an enormous increase in computer-mediated communication (CMC). CMC includes a variety of electronic message systems and electronic conference systems, which can be supplemented by audio and video links. CMC can be synchronous (e.g., chat) or asynchronous (e.g., email), and the messages are predominantly typewritten (Anderson, 2001). Compared with email and other computer- assisted communication tools such as discussion forums, online chat rooms have a greater potential of enhancing language teaching and learning because they provide synchronous, real-time interaction among participants. Participants have to process what they read on the screen quickly and give their response instantaneously, appropriately, and to the point.

In teaching, feedback refers to comments or other information that learners receive concerning their success on learning tasks or tests, either from the teacher or other person. We have different kinds of feedback like: Auditory Feedback, Kinesthetic Feedback, Proprioceptive Feedback, and Error Correction (Richards\& Schmidt, 2002).Aiming to investigate the enhancement of EFL learners' self-repair, the present study focused specifically on this type of error correction among all the other kinds of feedback.

Error correction and corrective feedback are the areas that bridge the concerns of EFL teachers, researchers, and instructional designers. As defined by Ellis (2007), error correction is a technique to help learners correct errors by providing them with some kind of prompting, and corrective feedback taking the form of responses to text containing an 
error. Students can often correct themselves when they realize they have made a mistake. Sometimes their mistakes are simply a "slip" and they are aware of the correct version. So, one choice for teachers would be to give students a chance and time to correct themselves. As stated by Liebscher and Dail- O'cain (2003), self-repair takes place when speakers correct their own speech. The purpose of the current research is, therefore, to investigate whether on-line chatting can enhance EFL learners' performance through self-repair. The following sections provide an overview of on-line learning focusing on on-line chatting and feedback focusing on error correction and self-repair.

\section{BACKGROUND}

\section{A. An Overview of On-line Learning}

In spite of their multiple commitments in their adult lives, instructors refer to on-line learning as available alternative to accomplish academic goals. It has had a consistent growth rate for at least 10 years (Livingston \& Wirt, 2004), and is defined as:

"The use of the Internet to access learning materials; to interact with the content, instructor, and other learners; and to obtain support during the learning processes, in order to acquire knowledge, to construct personal meanings, and to grow from the learning experience." (Alley, 2004).In on-line discussion, for example, all students have a voice and no one, not even an instructor, can dominate the conversation, accordingly, many researchers note that students perceive on-line discussion a more equitable and more democratic than traditional class room discussions (Harasim, 1990; Levin, Kim, \& Riel,1990). Because it is asynchronous, on-line discussion also affords participants the opportunity to reflect on their classmates' contributions while creating their own, and to reflect on their own writing before posting it. This creates certain mindfulness among students and a culture of reflection in course discussion (Garrison, 2003; Hiltz, 1994; Poole, 2000).

(Barile \& Durso, 2002) and (Basque \& Pudelko, 2004), and Dennis (2003) found that the use of a chat tool proved to be as effective as face-to-face communication in collaborative writing tasks. Furthermore, Ruberg, Moore, and Taylor (1996) found that synchronous computer-mediated communication leads to more experimentation, sharing of ideas, increased and more distributed participation compared to face-to-face communication. Finally,(Condon \& Cech, 1996a) and (Condon \& Cech, 1996b) and (Jonassen \& Kwon ,2001) show that groups who use computer-mediated chat compensate for the communication constraints by being more concise in their interactions. They found that students using a chat tool eliminate unnecessary elaborations and repetitions, and seek to increase the efficiency of their communication because of the slower pace of interaction.

\section{B. Feedback}

The study of feedback has permeated research on human behavior in organizations. Obviously, feedback is important. Unfortunately, the obviousness of its importance is not matched by the level of detail with which it has been studied. A review of current research on feedback suggests the need to understand feedback as part of broad organizational processes. The role of feedback as a fundamental organization subsystem is then developed, introducing additional variables necessary to understand the feedback process. The resulting framework is then applied to the integration of the recently acquired business. A feedback systems perspective is used to analyze several cases in which problems emerged following the acquisition and to consider intervention alternatives. (Narciss \& Huth, 2006).

\section{Error Correction}

According to Schegloff, Jefferson, and Sack (1977), error correction or" conversational repair" is a mechanism which used to deal with trouble is speaking or understanding". Leibscher and Dailey-O'Cain (2003) argued that it consists of three components: The trouble source; the repair imitation, which is the indication is that there is a trouble to be repaired; and the outcome, which is the response to the repair attempt. To put it in Schegloff et al. words, repair mechanism included repair initiation in which there is no recognizable error.

\section{Self-repair}

Self-correction can be viewed as a global goal of language learning, since in the long run learners should be able to make self-initiated self-repair (Allwright \& Bailey, 1991). Reaching this goal, however, is problematic. If learners can identify their own errors and self-correct them, we might wonder why they made the error in the first place, especially for writing where learners can devote time to accuracy. Most approaches to self-correction, therefore, do not leave learners totally to their own devices, but require teachers to provide some support. Usually, this support involves detecting and pointing out the errors, while leaving the actual correction to the learners (Makino, 1993). Thus, this study focuses on this kind of error correction (i.e., self-repair) through on-line chatting and face-to-face class discussions.

\section{STATEMENT OF THE PROBLEM}

With the advancements in information technology, there has been a growing interest in the use of computer network for second/foreign language situation. Many people consider chat not as a tool of communication but as a tool for wasting their time. On-line chatting enables learners to speak with reduced anxiety and it allows learners to conceal personal information such as race and gender that might lead to positive/negative effects in oral performance in EFL. 
Unlike the real world in which people may be sensitive to others' race and gender as the important factors for making friends, this is not the case in the chat rooms.

In conveying the messages spoken or written, students most probably do not pay due attention to their mistakes whether grammatical or lexical. They just want to communicate believing those mistakes do not block the communication process. In English classes neither peer nor self-correction was found to be taken place on the part of students in the case of grammatical or lexical mistakes. The only correction observed was actually made by teachers either explicitly or implicitly. With regard to this fact, and according to the interview conducted with some EFL teachers and based on the researcher's own experience as an English teacher, it is obvious that most students after passing some English courses still do not care about their grammatical and lexical mistakes, more precisely; they do not care about accuracy of their speech. Therefore, the present study is an attempt to examine the EFL language learners' occurrence of self-repairs in their on-line chatting in comparison with face-to-face class discussions and also to investigate the number of self-repairs in both groups. Findings from this study may help language teachers to come to a better understanding of the value of electronic online chat, and encourage them to use on-line chatting as a fruitful tool to provide a pleasant environment and promote students' willingness to interact in the target language. It is also hoped that the findings make the teachers well aware of the advantages of self-repair over other types of repair.

\section{RESEARCH QUESTIONS}

As mentioned earlier, the current study aims to shed light on the impact of self-repair through on-line chatting and face-to-face class discussions on EFL learners' accuracy by addressing the following major questions:

1. Does self-repair affect the grammatical and lexical knowledge of EFL learners equally in both on-line chatting and face-to-face class discussion?

2. Are the numbers of EFL learners' self-repairing their utterances the same in on-line chatting and face-to-face class discussion?

3. What are the most common problematic areas for on-line chatters and students in face-to-face class discussion in terms of accuracy of their speech?

\section{RESEARCH HYPOTHESES}

These questions can be reformulated as the following null hypotheses:

1. Self-repair does not affect the grammatical and lexical knowledge of EFL learners equally in both on-line chatting and face-to-face class discussion.

2. The number of self-repair occurrences is equal in both on-line chatting and face-to-face class discussion.

\section{METHOD}

\section{A. Participants}

Initially, 80 EFL learners were randomly selected. They were female students within the age range of 14-18. To make sure about their levels of language proficiency at the time of study, a standard OPT (Edwards, 2009) was administrated and 50 homogeneous intermediate learners were selected. Then, to gather information about the participants' literacy and familiarity with computer, Internet, and on-line chatting, a pre-research questionnaire was administered at the first session. Finally, following the students' answers to the questionnaire, 40 learners were selected to serve as the final participants of the present study. Students were randomly divided into two on-line chatting treatment and face-to-face class discussion treatment groups. The on-line chatting treatment group was asked to chat and put their grammatical and lexical knowledge into practice; while, the face-to-face class discussion treatment group participated in their regular class discussions.

\section{B. Materials}

\section{Oxford Placement Test (OPT)}

The OPT (Edwards, 2009) was administrated to assess the current level of language proficiency of the groups. In fact, it was used to exclude from the study those learners whose language proficiency level differed significantly from that of others. According to the attached scoring chart of the OPT, those students whose score was above 31 , were selected as intermediate. The OPT included 50 multiple choice questions which assessed students' knowledge of key grammar and vocabulary, a reading text with 10 graded comprehension questions and an optional writing task that assessed students' ability to produce the language.

\section{Pre-Research Questionnaire}

To gather information about the participants' literacy and familiarity with computer, Internet, and on-line chatting, a pre-research questionnaire was administered at the first session. In fact, it was used to exclude from the study those learners who did not have familiarity with computer especially Internet and on-line chatting.

\section{Pre and Post- tests}

To assess the learners' knowledge of grammar and vocabulary, a standard multiple choice pre-test (Allen, 2004) was given to both groups of the participants. The pre-test consisted of 60 questions. Since only 40 questions were used in the 
present study, after piloting the test, its reliability was established. It was .917 which was significant at $p=, 000$. So, the results turned out to have sufficient reliability. For the post test, three months later the same procedure was followed.

\section{Yahoo Messenger Software}

The software used in this study for on-line chatting treatment group was the Yahoo Messenger. All students had an ID for chatting. Both the researcher and the participants added each other's IDs to their contact lists. Therefore, students and the researcher could chat (in a written form) with each other privately. The program, could record all the written transcriptions entered in chat window. This provided the researcher with an instantaneous transcript of all user exchanges, and all the written transcripts could conveniently be printed.

\section{Voice Recorder}

The instrument used in this study for face-to-face class discussion treatment group was a voice recorder. For further analysis, students' discussion was recorded by the voice recorder.

\section{DATA ANALYSIS}

\section{A. Research Question 1}

Research question one focuses on whether self-repair affected the grammatical and lexical knowledge of EFL learners equally in both on- line chatting and face-to-face class discussion. In order to answer this research question a pretest and a posttest were employed to both treatment groups, that is, chat group and discussion group. Table 4.1 reveals the descriptive statistics for these two tests and Figure 4.1 illustrates the means in bar chart.

TABLE 4.1.

DESCRIPTIVE STATISTICS FOR THE PRETEST AND POSTTEST

\begin{tabular}{|lcccccc|}
\hline Test & Group & N & Min & Max & Mean & SD \\
\hline Pretest & Chat & 20 & 31 & 37 & 33.90 & 1.553 \\
& Discussion & 20 & 31 & 35 & 33.20 & 1.282 \\
\hline \multirow{2}{*}{ Posttest } & Chat & 20 & 34 & 39 & 36.70 & 1.582 \\
& Discussion & 20 & 32 & 38 & 34.80 & 1.908 \\
\hline
\end{tabular}

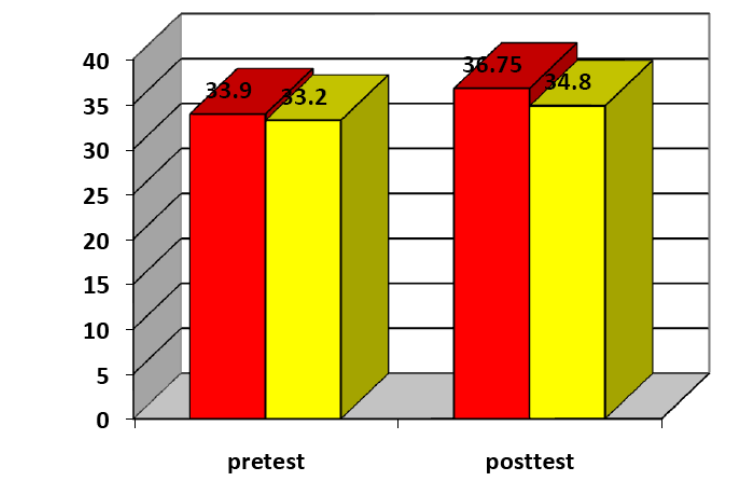

Figure 4.1.Graphical Representation of the Pretest and Posttest Means

It can be seen in the above figure that the means of the groups are different for both the pretest and the posttest. First, in order to see if the difference between the pretests was statistically significant or not, a t-test was employed. Table 4.2 shows the results of the t-test for the pretest.

TABLE 4.2.

THE RESULTS OF THE T-TEST ON THE PRETEST

\begin{tabular}{cccc}
\multicolumn{4}{c}{ THE RESULTS OF THE T-TEST ON THE PRETEST } \\
\hline $\mathrm{t}$ & $\mathrm{df}$ & $\mathrm{p}$ & Mean Difference \\
\hline 1.555 & 38 & .128 & .70 \\
\hline
\end{tabular}

The statistics in Table 4.2 indicates that the amount of t-observed $(\mathrm{t}$-observed $=1.555, \mathrm{p}=.128)$ is not high enough to denote a statistically significant difference between the two groups; therefore, it can be claimed that the two groups were not different in their language proficiency at the beginning of the experiment.

At the end of the experiment another test was administered to find out which treatment produced better effects in the participants. By referring to Table 4.1, one can see that the performances of the two groups were not the same. Again, to understand if this difference between the groups was statistically significant or not another t-test was implemented. Table 4.3 depicts the results of this second t-test. 
TABLE 4.3.

THE RESUlTS OF THE T-TEST ON THE POSTTEST

\begin{tabular}{llll}
\hline $\mathrm{t}$ & $\mathrm{df}$ & $\mathrm{p}$ & Mean Difference \\
\hline 3.545 & 38 & .001 & 1.95 \\
\hline
\end{tabular}

With regard to Table 4.3, it can be understood that the amount of t-observed (t-observed $=3.545)$ is significant at the probability level of $\mathrm{p}=.001$ which is statistically significant. In other words, the chat group outperformed the discussion group in the posttest. Therefore, it can be said that online chatting produced a better effect in participants' self-repair than face-to-face class discussion. So, the first null hypothesis is rejected.

\section{B. Research Question 2}

Research question two asks whether the numbers of learners' self-repairing their utterances are the same in an on-line chatting and face-to-face class discussion. To address to this question the number of self-corrections for both groups was counted separately. Table 4.4 shows the total number of self-corrections for individual participants in all sessions.

TABLE 4.4.

THE NUMBER OF SELF-CORRECTIONS FOR EACH PARTICIPANT

\begin{tabular}{|c|c|c|}
\hline Participants & Chat Group & Discussion Group \\
\hline 1 & 10 & 15 \\
\hline 2 & 10 & 18 \\
\hline 3 & 4 & 21 \\
\hline 4 & 12 & 18 \\
\hline 5 & 3 & 15 \\
\hline 6 & 8 & 18 \\
\hline 7 & 4 & 15 \\
\hline 8 & 7 & 15 \\
\hline 9 & 8 & 13 \\
\hline 10 & 4 & 18 \\
\hline 11 & 5 & 16 \\
\hline 12 & 6 & 18 \\
\hline 13 & 16 & 14 \\
\hline 14 & 9 & 12 \\
\hline 15 & 6 & 13 \\
\hline 16 & 2 & 17 \\
\hline 17 & 2 & 12 \\
\hline 18 & 9 & 17 \\
\hline 19 & 4 & 16 \\
\hline 20 & 2 & 14 \\
\hline Total & 131 & 315 \\
\hline
\end{tabular}

Then, in order to find out whether or not the difference between the numbers of self-corrections for the two groups was significant, a chi-square was employed. Table 4.5 shows the results of this test.

TABLE 4.5.

THE RESULTS OF THE CHI-SQUARE FOR SELF-CORRECTIONS

\begin{tabular}{lll}
\hline$\chi^{2}$ & $\mathrm{df}$ & $\mathrm{p}$ \\
\hline 33.173 & 19 & .023 \\
\hline
\end{tabular}

By checking Table 4.5 , one can see that the amount of chi-square $\left(\chi^{2}=33.173\right)$ is significant at the probability level of $\mathrm{p}=.023$ which represents a statistically significant difference. In other words, the chat group used fewer selfcorrections than the discussion group. Thus, second null hypothesis is also rejected.

\section{Research Question 3}

Research question three focuses on the most common problematic areas for on-line chatters and students in face-toface class discussion in terms of accuracy of their speech. In order to answer this research question some qualitative data analyses were conducted.

\section{The Problematic Areas of On-line Chatters}

Figure 4.2 shows the problematic areas of on-line chatters.

\begin{tabular}{|l|}
\hline Verbs (Subject-verb agreement and verb tenses) \\
Articles \\
Word Choice \\
Propositions \\
Plural /s/ \\
Spelling \\
Word order \\
Figure 4.2.Problematic Areas of the On-line Chatters
\end{tabular}


Then the number of correcting attempt by the students was calculated for each of the above area for each group. Table 4.6 indicates this calculation, and Figure 4.3 shows the percentage of the errors graphically.

TABLE 4.6.

NUMERICAL BREAKDOWNS OF ERROR TYPES

\begin{tabular}{|l|l|l|}
\hline Error type & Number of errors & Percentage \\
\hline Verbs(Subject-verb agreement)and tense & 32 & 24.43 \\
\hline Articles & 27 & 20.61 \\
\hline Word Choice & 25 & 19.08 \\
\hline Preposition & 20 & 15.27 \\
\hline Plural/s/ & 15 & 11.45 \\
\hline Spelling & 8 & 6.11 \\
\hline Word order & 4 & 3.05 \\
\hline Total & 131 & 100 \\
\hline
\end{tabular}

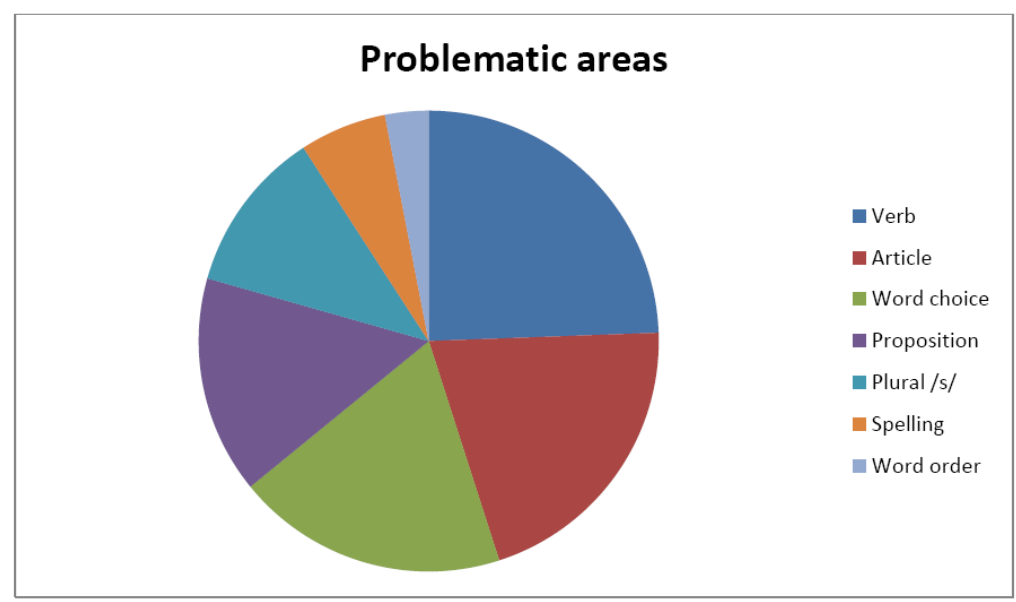

Figure 4.3. Graphical Representation of the Problematic Areas for On-line Chatting Group

In total, 131 occurrences of different types of error were identified for the on-line chatting group. These included errors in verbs (subject-verb agreement) and tense, word choice, articles, prepositions, plural/s/, spelling, and word order. We can see from the above table that most common type of errors belonged to the subject-verb agreement and verb tenses, accounting for almost $24.43 \%$ of the total number of errors. On the contrary, the less common type of errors belonged to word order, accounting for $3.05 \%$ of the total number of errors. Therefore, according to the data collected from printouts of on-line chatting and the subsequent data analysis, most problematic areas of on-line chatter were determined.

\section{The Problematic Areas of Students in Face-to-face Class Discussion}

For understanding problematic areas of students in face-to-face class discussion treatment group the same procedure was followed.

Figure 4.4 shows the problematic areas of students in face-to-face class discussion group.

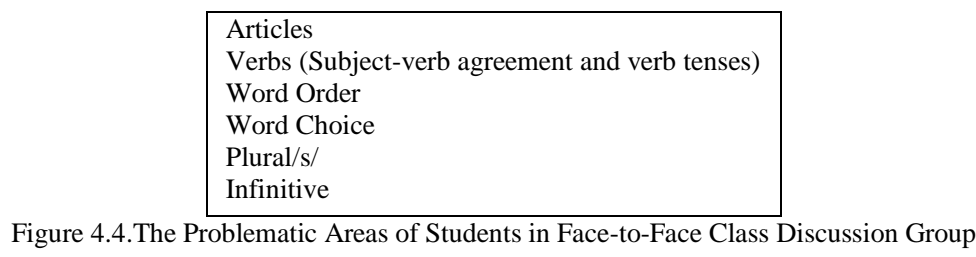

Having known the problematic areas of students in face-to-face class discussion, the researcher calculated the numerical breakdowns of the error types. Table 4.7 indicates this calculation, and Figure 4.5 shows the percentage of the errors graphically.

TABLE 4.7.

NUMERICAL BREAKDOWNS OF ERROR TYPES

\begin{tabular}{|l|l|l|}
\hline Error type & Number of errors & Percentage \\
\hline Articles & 65 & 20.63 \\
\hline Verbs(Subject-verb agreement and tense) & 60 & 19.05 \\
\hline Word Order & 58 & 18.42 \\
\hline Word Choice & 54 & 17.15 \\
\hline Plural/s/ & 50 & 15.87 \\
\hline Infinitive & 28 & 8.88 \\
\hline Total & 315 & 100 \\
\hline
\end{tabular}




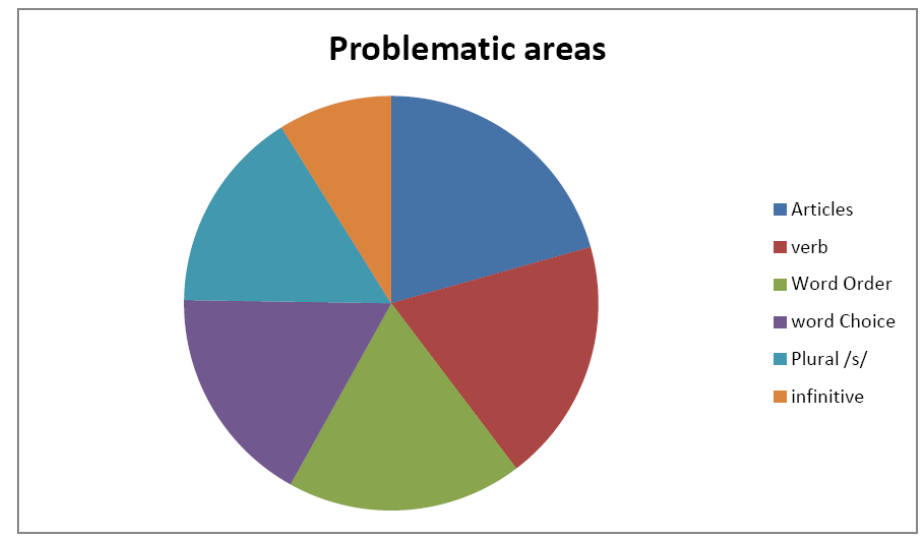

Figure 4.5.Graphical Representation of the Problematic Areas for Students in Face-to-face Class Discussion Group

In total, 315 occurrences of different types of error were identified for the students in face-to-face class discussion. These included errors in articles, verbs (subject-verb agreement) and tense, word order, word choice, plural /s/, and infinitive. We can see from the above table that most common type of errors belonged to the articles, accounting for $20.63 \%$ of the total number of errors. On the contrary, the less common type of errors belonged to infinitive, accounting for $8.88 \%$ of the total number of errors. A detailed discussion of the results will be presented in the next chapter.

\section{DISCUSSION}

The previous section presented the analysis and results for each research question. This section will discuss those results with the goal of bringing together the findings from the various analyses in order to create an overall picture of self-repair in both on-line chatting and face-to-face discussion.

\section{A. Research Question 1}

Concerning the first research question, i.e., "Does self-repair affect the grammatical and lexical knowledge of EFL learners equally in both on- line chatting and face-to-face class discussion?" , self-repair didn't seem to affect the grammatical and lexical knowledge of EFL learners equally in both on-line chatting and face-to-face class discussion. These findings are in line with earlier research conducted by Pellettieri (2000) according to which better comprehension, more successful communication, and a greater quantity of target language production were achieved through negotiation of meaning in on-line chatting. Moreover, Ruberg, Moore, and Taylor (1996) found that synchronous computer-mediated communication leads to more experimentation, sharing of ideas, increased and more distributed participation compared to face-to-face communication.

\section{B. Research Question 2}

Regarding the second research question, i.e., "Are the numbers of learners' self-repairing their utterances the same in an on-line chatting and face-to-face class discussion?" the number of correction made by the chat group was smaller than that of the discussion group. The reason for this result can be attributed to the fact that since in on-line chatting, due to the advantageous nature of chat as a written communication, students could type and saw their messages simultaneously, and whenever they saw a question mark or an emoticon which was the symbol of error, they initiated to self-repair, and they never forgot their own messages or even the word which was incorrect because they constantly could check and revise their written messages. Thus, they corrected their committed errors in one attempt or, in some cases, in two.

In contrast, students in face-to-face class discussion were deprived of the benefits of checking their conversation whenever they decided to because it was only oral and they had to use their memory to remember what they said. In some cases, because of not remembering their exact words, they attempted to make another mistake besides the one they made in their first utterance and in some cases the structure of their sentences was changed; therefore, this made them to commit to more self-corrections. That's why the number of self-repairs was higher in this group as compared to the chat group. These findings are in line with earlier researches conducted by Condon and Cech, (1996a \& b). They believed that, since written messages have more permanence than spoken utterances, students have more time to process incoming messages through chat. This would mean that they are able to interpret complex instructions more easily than in spoken interaction. In addition, computer-mediated chat allows students to revise messages before they send them which would facilitate the composition of more precise and concise instructions. Chat may give students more time to plan clearer, less ambiguous instructions and messages than are usually found in spoken dialogues, where there is a constant pressure to keep the interaction going. Students communicating through chat have more time to process incoming messages. Thus, both studies aimed to say that students are able to interpret and correct complex instructions more easily than in spoken interactions.

\section{Research Question 3}


Addressing the third research question "what are the most common problematic areas for on-line chatters and students in face-to-face class discussion"? , the most common types of errors belonged to the subject-verb agreement and verb tenses for the on-line chatters and articles for the students in face-to-face class discussion group. This may indicate that the use of subject-verb agreement, verb tense and article are perhaps difficult items for the Iranian EFL learners to learn, and that is why students after passing some English courses either in institutes or universities, still cannot speak accurately. The obtained results of this study are in contrast to earlier research conducted by Yuan (2003). The difference between the findings of this study and the previous one can be attributed to the fact that the participants in Yuan's study were ESL university male professors; while in this study they were female EFL intermediate learners. So, one can find out that participants were different in terms of age, sex, language proficiency, and the settings in which they learned English (i.e., SL and FL). That is why, Yuan (2003) determined the most common problematic areas for online chatters as word form/selection; while, in the present study the most common problematic areas were subject-verb agreement, especially third person /s/ for on-line chatters.

\section{IMPLICATIONS}

This study can have some pedagogical implications for the teachers, students and syllabus designers.

The results are also useful for language teachers. Language teachers should promote the students' positive attitude toward academic English learning. They should create a lively, challenging and non-threatening atmosphere for learning where the effective barriers are kept at minimum.

Another point which is worth mentioning is that at the end of the experiment with on-line chatters, all students mentioned that they had enjoyed the on-line chatting as it was an exciting and interesting way to improve their grammatical and lexical knowledge resulting in accurate speaking. They also said that it was a departure from the usual classroom environment and enthusiastically asked for more on-line chatting. Therefore, interested teachers can try the experience of on-line teaching and help their students improve and put to use their English language knowledge.

Last, but not least, considering the situation of EFL in Iran, syllabus designers and material developers had better use the benefits of on-line chatting in their text books. In other words, since one of the most common problematic areas for Iranian EFL learners is subject-verb agreement and verb tenses, they can provide much more about these items in their textbooks so that students may improve their problems regarding such items.

\section{LiMITATIONS}

When considering the implications of the study, discussed above, there are several limitations that researchers and teachers should be aware of.

1. One of the biggest disadvantages and drawbacks for using on-line chatting in Iran is the cost. Connecting schools to the Internet is very costly. That is why the participants and the researcher accessed the chat room facilities from their houses.

2. Some of the students were slow in typing their messages. As a result, chat's time exceeded 45 minutes in some cases.

3. The number of participants is limited to only 40 intermediate students; however, to increase the reliability of the study more participants at other levels of proficiency should be included.

\section{SUGGESTION FOR FUTURE RESEARCH}

This study aimed to answer a limited number of questions raised in the first chapter. This is while many other questions may be raised as the followings:

1. In this study, only one proficiency level (i.e. intermediate) was included. It is suggested that learners in other age groups participate in further studies.

2. The participants in this study were all female learners. Thus, another study can be investigated male students' performance in on-line chatting.

3. The students who participated in this study were all from a single language background, i.e. Persian. In a more extensive research of this kind, students from a range of language background can be selected.

4. This study used the messages corresponded among the EFL learners; other studies can be conducted following the same procedure to identify the effects of self-repair enhancement among the members of other academic or professional communities.

5. Other studies can be carried out to find out the use of on-line chatting as an effective tool in collaborative writing tasks.

\section{CONCLUSION}

The results discussed above demonstrated that on-line chatters produced a better performance with regard to selfrepair. Such self-repairs were useful because they showed the students' awareness and conscious knowledge of the 
language. By studying the self-repair, one would understand the learners' linguistic knowledge and abilities better and, therefore, offer a more appropriate program for them.

With regard to noticing errors, Richard Schmidt's Noticing Hypothesis (1990) stated that "noticing is the necessary and sufficient condition for converting input to intake" (p.129). According to Schmidt (1990), noticing meant focal awareness (p.132) whereas "in-take meant once something is noticed by the learner".

In the present study, it was seen that class discussions may have increased the salient grammatical/lexical forms in English, but on-line chatting enabled students to put those grammatical/lexical knowledge which was learned theoretically in class to practice in a meaningful communication.

Secondly, it was shown that chat group used fewer self-repairs than face-to-face discussion group. This shows that due to the nature of chat as a written communication and students' accessibility to written form of their messages, they corrected their messages in a fewer number of attempts than the students in face-to-face class discussion. These findings lead us to conclude that on-line chatting activities enable the learners to attend to both linguistic forms and communicative contents, resulting in meaningful communication in more accurate linguistic forms. In addition, self-repairs in the flow of spontaneous on-line interaction gave the researcher a chance to see certain learning processes that the learners went through when they tried to negotiate meaning in their foreign language, a process that would otherwise be difficult to observe. For example, it was found that most of the errors the learners committed belonged to the categories of subject-verb agreement and verb tenses for the on-line chatters and articles for those students in face-to-face class discussion group, presumably because such errors would often jeopardize the accurate speaking.

Finally, It can be claimed that, based on the results of the present study, a supplementary on-line learning environment may enhance language learning and development. When learners notice the linguistic forms they have learned in class in a real language situation such as on-line chat rooms, they can convert their input into in-take, thus making language acquisition possible.

\section{REFERENCES}

[1] Allen, D. (2004). Oxford placement test. Oxford: Oxford University Press.

[2] Alley, M. (2004). Foundation of educational theory for on-line learning. In T. Anderson \& F. Elloumi (Eds.), Theory and practice of on-line learning (pp. 3-31). Athabasca: Athabasca University.

[3] Allwright, D., \& Bailey, K. M. (1991). Focus on the language classroom: An introduction to classroom research for language teachers. Cambridge: Cambridge University Press.

[4] Anderson, L. (2001). Gender and computer-mediate communication: Group process in problem solving. Computer in Human Behavior, 17, 71-94.

[5] Barile, A. L, \& Durso, F. T. (2002), Computer-mediated communication in collaborative writing. Computers in Human Behavior, 18, 173-190.

[6] Basque, J., \& Pudelko, B. (2004). The effect of collaborative knowledge modeling at distance on performance and on learning. Paper presented at the first international conference on concept mapping (14-17 September, 2004) Pamplona, Spain.

[7] Condon .S. L., \& Cech. C. G. (1996a). Functional comparison of face-to-face and computer-mediated decision-making interactions. In S.C. Herring (Ed.), Computer-mediated communication; Linguistic, social, and cross-cultural perspectives (pp. 65-80). Amsterdam: John Benjamins.

[8] Condon .S.L., \& Cech. C. G. (1996b). Discourse management in face-to-face and computer-mediated decision-making interactions. Electronic Journal of Communication, 6(3). Retrieved March3, 2010, from http://www.cios.org/EJCPUBLIC/006/3/00631.html

[9] Dennis, J. K. (2003). Problem-based learning in on-line vs. face-to-face environments. Education for Health, 16(2), 198-209.

[10] Edwards, L. (2009). Oxford placement test. Oxford: Oxford University Press.

[11] Ellis, R. (2007). Corrective feedback in theory, research and practices. A keynote speech in The 5th Annual International Conference on ELT in Beijing, video and PowerPoint. Retrieved June 1, 2010, from http://www.celea.org.cn/2007/edefault.asp

[12] Garrison, D. R. (2003). Cognitive presence for effective asynchronous online learning: The role of reflective inquiry, selfdirection and metacognition. In J. Bourne \& J. C. Moore (Eds.), Elements of quality online education: Practice and direction (pp. 47-58). Needham, MA: Sloan Center for Online Education.

[13] Geri, N., \& Gefen, D. (2007). Is there a value paradox of e-learning in MBA Program? Issues in Informing Science and Information Technology, 4, 163-174.

[14] Greenfield, P. M. (1984). Mind and media: The effects of television, video games, and computers. Cambridge, MA: Harvard University Press.

[15] Harasim, L. (Ed.). (1990). Online education: Perspectives on a new environment. New York: Praeger.

[16] Herring, S. C. (1999). Interactional coherence in CMC. Journal of Computer Mediated Communication, 4 (4). Retrieved February 6, 2010, from http://jcmc.indiana.edu/vol4/issue4/herring.html

[17] Hiltz, S. R. (1994). The virtual classroom: Learning without limits via computer networks. Norwood, NJ: Ablex.

[18] Hiltz, S. R., \& Turoff, M. (2005). Education goes digital: The evaluation of online learning and the revolution in higher education. Communication of the ACM, 48(10), 59-64. Retrieved February 20, 2010 from http://schfstud1.hsh.no/hfag/litteratur/jenssen/deosnews/mason.htm

[19] Jonassen, D. H., \& Kwon, H. L. (2001). Communication patterns in computer- mediated versus face-to-face group problem solving. Educational Technology Research and Development, 49(1), 35-51.

[20] Levin, J. A., Kim, H., \& Riel, M. M. (1990). Analyzing instructional interactions on electronic message networks. In L. M. Harasim (Ed), Online education: Perspectives on a new environment (pp. 185-213). New York: Praeger. 
[21] Liebscher, G., \& Dailey-O Cain, J. (2003). Conversational repair as role defining mechanism in classroom interaction. The Modern Language Journal, 87, 375-390.

[22] Livingston, A., \& Wirt, J. (2004). The condition of education 2004 in brief. Washington DC: US Government Printing Office.

[23] Makino, T. (1993). Learner self-correction in ESL written compositions. ELT Journal, 47, 337-341.

[24] Narciss, S., \& Huth, K. (2006). Fostering achievement and motivation with bug-related tutoring feedback in a computer-based training for written subtraction. Learning and Instruction, 16, 310-322.

[25] Pellettieri, J. (2000). Negotiation in cyberspace: The role of chatting in the development of grammatical competence. In M. Warschauer \& R. Kern (Eds.), Network- based language teaching: Concepts and practice (pp. 59-86). Cambridge: Cambridge University Press.

[26] Poole, D. M. (2000). Student participation in a discussion-oriented online course: A case study. Journal of Research on Computing in Education, 33(2), 162-177.

[27] Richards, J. C, \& Schmidt, R. (2002). Longman dictionary of language teaching and applied linguistics. ( $3^{\text {rd }}$ Ed.), Pearson Educated Limited.

[28] Ruberg, L. F., Moore, D. M., \& Taylor, C. D. (1996). Student participation, interaction, and regulation in a computer-mediated communication environment: A qualitative study. Journal of Educational Computing Research, 14(3), 243-268.

[29] Schmidt, R. W. (1990). The role of consciousness in second language learning. Applied Linguistic, 11, 129-158.

[30] Shegloff, E. A., Jefferson, G., \& Sack, H. (1997). The preference for self-correction in the organization of repair in conversation. Language, 53, 261-382.

[31] Yuan, Y. (2003). The use of chat rooms in an ESL setting. Computers and Composition, 20(2), 194-206.

Omid Tabatabaei received his B.A. in translation in 1994 and M.A. in teaching English as a foreign language (TEFL) in 1997, and then his Ph.D in TEFL in 2007. He earned all the mentioned degrees from Iranian Universities.

$\mathrm{He}$ is presently an assistant professor at Islamic Azad University, Najafabad Branch, head of English Department and vice-dean of the Faculty of Humanities and Literature.

He has published a couple of articles at national and international journals and presented papers at national and international conferences. His areas of interest are language acquisition, testing and assessment, teaching skills, and psycholinguistics.

Razieh Sharifi received her M.A. in TEFL from Islamic Azad University, Shahreza Branch. She is an English teacher and has been teaching at language institutes for about four years. 